\title{
Beta-adrenergic Stimulation of Adenine Nucleotide Catabolism and Purine Release in Human Adipocytes
}

Horst Kather

Klinisches Institut für Herzinfarktforschung an der Medizinischen Universitätsklinik Heidelberg, Bergheimerstrasse 58, D-6900 Heidelberg, Federal Republic of Germany

\begin{abstract}
The effects of $\beta$-adrenergic agonists on ATP utilization and adenine nucleotide breakdown in human adipocytes were examined. The catecholamine-induced increase in cAMP was associated with an enhancement of adenine nucleotide catabolism resulting in an increase in release of inosine and hypoxanthine which can not be reutilized for adenine nucleotide synthesis. Therefore, one-third of total cellular adenine nucleotides were irreversibly lost in the presence of $1 \mu \mathrm{mol} /$ liter isoproterenol.

The catecholamine-induced increase in purine release could be blocked by phosphodiesterase inhibitors, suggesting that cAMP is the main precursor of purines in the presence of $\beta$-adrenergic agonists. However, epinephrine (in the simultaneous presence of the $\alpha_{2}$-adrenergic blocking agent, yohimbine) and isoproterenol were 10 times more potent in stimulating purine release than in elevating cAMP. In addition, purine release ceased when cAMP was still markedly increased, suggesting a compartmentation of the cyclic nucleotide and/or involvement of the hormone-sensitive, low $K_{\mathrm{m}}$ cAMP phosphodiesterase.

The results document that white fat cells have an enormous potential for dissipating energy, and demonstrate that the pathway involving CAMP formation and hydrolysis constitutes the principle route of adenine nucleotide catabolism in the presence of $\beta$-adrenergic agonists. (J. Clin. Invest. 1990. 85:106-114.) adenine nucleotides $\bullet$ adipocytes $\bullet$ purines
\end{abstract}

\section{Introduction}

It is well established that the activation of lipolysis by hormones may be associated with a decrease in ATP (1-3). The stimulatory effects of lipolytic hormones are mediated by cAMP (4). The concentrations of the cyclic nucleotide required to produce an increase in lipolytic activity are in the micromolar concentration range, while ATP concentrations are in the range of 5-10 mmol/liter (4). Accordingly, it is a widely held belief that ATP utilization via adenylate cyclase is small in relation to total ATP turnover, even when adenylate cyclase is maximally activated (4).

The hydrolysis of triglycerides does not require metabolic energy. Therefore, the effects of the products of lipolysis, e.g.,

Address correspondence to Dr. Horst Kather, Klinisches Institut für Herzinfarktforschung an der Medizinischen Universitätsklinik Heidelberg, Bergheimerstrasse 58, D-6900 Heidelberg, FRG. 1989.

Received for publication 19 April 1989 and in revised form 1 August

J. Clin. Invest.

(c) The American Society for Clinical Investigation, Inc.

0021-9738/90/01/0106/09 \$2.00

Volume 85, January 1990, 106-114
FFA and glycerol, on energy metabolism as well as the energetic requirements of their further metabolism have received considerable attention (1-9). Glycerol cannot be metabolized by human adipose tissue (5-8). By contrast, FFA can be degraded or reesterified (1-9). The triglyceride-FFA cycle requires metabolic energy and generates heat (5-8). In addition, FFA can uncouple oxidative phosphorylation and this effect may contribute to the drop in ATP seen in the absence of albumin, or when the FFA to albumin ratio in the media exceeds a value of $6(1-3,9)$.

A major problem in the determination of ATP turnover via adenylate cyclase has been the evaluation of the role(s) of phosphodiesterase(s). Quantitative estimates of the rates of cAMP hydrolysis revealed that, in contrast to commonly held views, human platelets display high rates of cAMP turnover even in the absence of activators (10). When rat adipocytes are incubated at low densities or in the presence of adenosine deaminase, most of the ATP may be converted to cAMP within minutes in the presence of lipolytic activators $(11,12)$. Accordingly, hormone-activated rates of cAMP turnover of rat adipocytes were too rapid to be quantified by current methodology (13).

Hydrolysis of cAMP yields AMP that is the first substrate of catabolic reactions (14). Any increase in its rate of synthesis can therefore lead to its further metabolism by dephosphorylation or deamination (14). Indeed, previous studies from this laboratory revealed that isoproterenol caused an increase in the release of inosine and hypoxanthine in human adipocytes which appeared to be related to ATP turnover via adenylate cyclase (15). The current studies are a detailed investigation into the interrelationship between lipolytic activity, cAMP accumulation, adenine nucleotide breakdown, and purine release in human adipocytes. It is shown that adenylate cyclase may constitute a major route of ATP utilization in human adipocytes in the presence of $\beta$-adrenergic agonists. The increase in cAMP is associated with an enhanced release of purines that cannot be reutilized for adenine nucleotide synthesis. Prolonged $\beta$-adrenergic stimulation therefore leads to an irreversible depletion of cellular energy stores.

\section{Methods}

\section{Subjects}

Fat tissue was from female subjects undergoing elective abdominal or cosmetic breast surgery who were not selected on the basis of age or weight. The subjects were operated on after an overnight fast. Anesthesia was initiated with a short-acting barbiturate and maintained with halothane, nitrous oxide, and oxygen.

\section{Preparation of fat cells}

Tissue specimens were cut into small pieces and fat cells were isolated by the method of Rodbell (16) in Krebs-Henseleit bicarbonate buffer, pH 7.4, containing $20 \mathrm{~g} /$ liter human serum albumin, $5 \mathrm{mmol} / \mathrm{liter}$ 
glucose, and $1 \mathrm{mg} / \mathrm{ml}$ collagenase (Worthington Biochemical Corp., Freehold, NJ). After $30 \mathrm{~min}$ of incubation fat cells were washed three times and resuspended in the same buffer (except that collagenase was omitted). In experiments where ectophosphatase activities were inhibited $\alpha, \beta$-methylene adenosine 5 -diphosphate $(10 \mu \mathrm{mol} /$ liter $)$ and $\beta$ glycerophosphate $(10 \mathrm{mmol} / \mathrm{liter})$ were added to the buffer during the last wash.

\section{Incubations}

Immediately after washing $10-15 \mathrm{ml}$ of cell suspensions were transferred to plastic scintillation vials containing hormones and enzymes as indicated in legends to figures and tables. Appropriate dilutions of inhibitors and hormones were made immediately before the start of incubations. 1-Methyl-3-isobutylxanthine (IBMX; $1.3 \mathrm{mmol} / \mathrm{liter})^{1}$ was dissolved in $0.154 \mathrm{~mol} /$ liter $\mathrm{NaOH}$ and neutralized with $1 \mathrm{~mol} /$ liter $\mathrm{HCl}$. The latter solution was used instead of $0.154 \mathrm{~mol} / \mathrm{liter} \mathrm{NaCl}$ for preparation of a Krebs-Henseleit bicarbonate buffer containing 1 $\mathrm{mmol} /$ liter IBMX. Stock solutions of 4-(3-butoxy-4-methoxybenzyl)2-imidazolidinone (Ro 20-1724; $200 \mathrm{mmol} / \mathrm{liter}$ in ethanol) were diluted to yield a maximal final ethanol concentration of $0.5 \%$, which had no influence on cell integrity or biological response. Incubations were performed at $37^{\circ} \mathrm{C}$ under an atmosphere of $95 \% \mathrm{O}_{2}$ and $5 \% \mathrm{CO}_{2}$ as described (15). ${ }^{2}$

To study the effects of phosphodiesterase inhibitors, cells were preincubated at $37^{\circ} \mathrm{C}$ in the presence of various concentrations of Ro 20-1724 or IBMX. After 30 min used media were replaced by fresh ones and incubations were continued for another 30-90 min as indicated in the legends to figures and tables. Alternatively, the washing step was omitted and isoproterenol was added after $15 \mathrm{~min}$ of preincubation. Untreated controls were handled in the same manner as inhibitor-treated cells in both protocols, except that phosphodiesterase inhibitors were omitted.

At the times indicated, $0.3 \mathrm{ml}$ of suspensions were removed and extracted by $1 \mathrm{~mol} /$ liter perchloric acid. Another aliquot of suspensions was centrifuged through silicone oil $(6,000 \mathrm{~g}, 10 \mathrm{~s}) .0 .2 \mathrm{ml}$ of the cell-free infranatants were transferred to perchloric acid for determination of cAMP, adenine nucleotides, and fatty acids. The remaining portion of the media $(0.8 \mathrm{ml})$.was inactivated by heating $\left(95^{\circ} \mathrm{C}, 5 \mathrm{~min}\right)$ and assayed for glycerol and purines.

\section{Assays}

FFA and glycerol. FFA were determined bioluminometrically (17). To increase the dynamic range and speed of fatty acid conversion, the concentrations of ATP, CoA, fructose-6-phosphate, and acyl-CoA synthetase were increased. The medium for conversion of fatty acids contained $23 \mathrm{mmol} /$ liter Hepes, pH 8.0, $1.1 \mathrm{mmol} /$ liter KCl, $20 \mathrm{mmol} /$ liter arsenate, $1.1 \mathrm{mmol} /$ liter DTT, $2.9 \mathrm{mmol} / \mathrm{liter} \mathrm{MgCl}_{2}, 0.5 \mu \mathrm{mol} /$ liter EDTA, $1.2 \mathrm{mmol} /$ liter ATP, $8 \mathrm{mmol} / \mathrm{liter} \mathrm{NAD}, 1 \mathrm{mmol} / \mathrm{liter}$ CoA, $1 \mathrm{mmol} /$ liter fructose-6-phosphate, $33 \mathrm{U} / \mathrm{ml}$ triosephosphate isomerase, $280 \mathrm{mU} / \mathrm{ml}$ aldolase, $18 \mathrm{mU} / \mathrm{ml}$ glyceraldehyde phosphate dehydrogenase, $35 \mathrm{mU} / \mathrm{ml}$ acyl-CoA synthetase, and $100 \mathrm{mU} / \mathrm{ml}$ of the pyrophosphate-dependent fructose-6-phophate kinase. 0.05-ml samples were added to an equal volume of conversion medium and incubated for $1 \mathrm{~h}$ at $25^{\circ} \mathrm{C}$. After appropriate dilution (10 times) samples were assayed for fatty acid contents as described (17). Human serum albumin (Behring Werke Marburg, Marburg, FRG) contained 1 $\mu \mathrm{mol} / \mathrm{g}$ fatty acids leading to blank values of $20 \mu \mathrm{mol} / \mathrm{liter}$, a figure that permitted a determination of FFA release without prior delipidation. Glycerol was determined as published (18).

Purines. Adenosine, inosine, and hypoxanthine were measured by a chemiluminescent method using the peroxidase/luminol system as indicator reaction (19). For determination of the sum of individual

1. Abbreviations used in this paper: IBMX, 1-methyl-3-isobutylxanthine; LDH, lactate dehydrogenase; Ro 20-1724, 4-(3-butoxy-4-methoxybenzyl)-2-imidazolidinone.

2. Kather, H., unpublished observations. purines the assay was modified. $20-50-\mu 1$ samples were made up with water or standard (usually $0.1 \mu \mathrm{mol} /$ liter) to yield a final volume of 0.1 $\mathrm{ml}$. During a first step all purines were converted to hypoxanthine by adding an equal volume of $0.2 \mathrm{~mol} /$ liter $\mathrm{Na}_{2} \mathrm{HPO}_{4}$ buffer, $\mathrm{pH} \mathrm{8.2}$, containing $0.72 \mathrm{~g} /$ liter EDTA, $25 \mu \mathrm{mol} / \mathrm{liter}$ luminol, $1.5 \mathrm{U} / \mathrm{ml}$ peroxidase, $50 \mathrm{mU} / \mathrm{ml}$ nucleoside phosphorylase, and $2.4 \mathrm{U} / \mathrm{ml}$ adenosine deaminase. After 7 min light emission was initiated by adding another $0.1 \mathrm{ml}$ of phosphate buffer containing $8 \mathrm{mU} / \mathrm{ml}$ xanthine oxidase, 1.5 $\mathrm{U} / \mathrm{ml}$ peroxidase, and $25 \mu \mathrm{mol} /$ liter luminol.

Light emission was not influenced by catecholamines and phosphodiesterase inhibitors up to concentrations of $1 \mu \mathrm{mol} /$ liter (catecholamines), $0.3 \mathrm{mmol} / \mathrm{liter}$ (IBMX), and $1 \mathrm{mmol} / \mathrm{liter}$ (Ro 20-1724), respectively. Samples containing higher amounts of these latter agents were extracted with chloroform, and light output was corrected by internal standardization.

Other determinations. Adenine nucleotides were assayed bioluminometrically as described $(15,20)$. cAMP was determined by a commercially available RIA after acetylation (Amersham, Bucks, UK). Cell number was determined by counting all cells in appropriately diluted aliquots of suspensions. Lactate dehydrogenase (LDH) activity of cell-free media and suspensions was determined by a commercially available kit (Boehringer Mannheim GmbH, Mannheim, FRG) as described (15).

\section{Materials}

IBMX was purchased from Serva AG (Heidelberg, FRG). Ro 20-1724 was a gift of Hoffmann La Roche Company (Basel, Switzerland). The sources of the other reagents used have been given in a previous report (15).

\section{Results}

Effects of isoproterenol on lipolysis, cAMP accumulation, and adenine nucleotide concentrations. Fig. 1 shows time courses of glycerol and FFA release in the presence and absence of 1 $\mu \mathrm{mol} /$ liter isoproterenol. The changes in cAMP and adenine nucleotide concentrations were monitored simultaneously (Fig. 2). On the average, isoproterenol caused a fourfold increase in lipolytic activity. Isoproterenol-activated rates of lipid mobilization proceeded at linear rates. The molar FFA to glycerol ratio was close to the theoretical value of 3:1 in the absence and presence of isoproterenol, indicating that no reesterification took place under the conditions used. In another series of experiments $(n=4)$ carried out in the presence of 10 $\mu \mathrm{mol} /$ liter $\alpha, \beta$-methylene adenosine 5 -diphosphate and 10 $\mathrm{mmol} /$ liter $\beta$-glycerophosphate $\sim 15 \%$ of the fatty acids produced were recycled back to triglycerides in the absence and presence of isoproterenol (not shown).

Human adipocytes contained $20-30 \mathrm{nmol} / 10^{6}$ cells adenine nucleotides (Fig. 2). In controls the adenine nucleotides

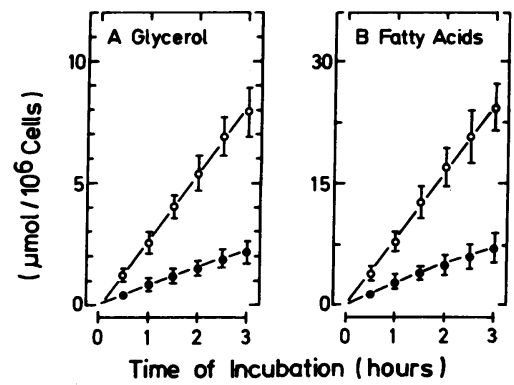

Figure 1. Release of glycerol $(A)$ and FFA $(B)$ in the absence and presence of isoproterenol. Isolated adipocytes $(20,000-40,000$ cells/ml) were incubated in the absence $(\bullet)$ or presence $(0)$ of 1 $\mu \mathrm{mol} /$ liter isoproterenol. Incubations were performed in the absence of ectophosphatase inhibitors. Values are means $\pm S E$ of eight paired experiments carried out with fat cells from different donors. 


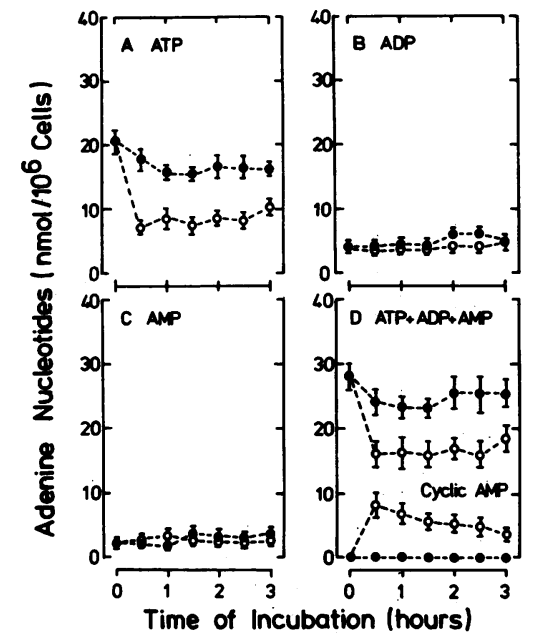

total cellular adenine nucleotide contents under these conditions. Symbols are the same as in Fig. 1.

$r$

were $74 \pm 6 \%$ ATP, $16 \pm 7 \%$ ADP, and $10 \pm 5 \%$ AMP. cAMP levels were $<1 \%$. The concentrations of ATP and total adenine nucleotides displayed an initial decline by $\sim 25 \%$, followed by a partial recovery, which may reflect a salvage of adenosine. Accordingly, the latter effect was not observed in the presence of dipyridamole, an inhibitor of nucleoside transport (not shown).

In the presence of isoproterenol ( $1 \mu \mathrm{mol} / \mathrm{liter}) \mathrm{ATP}$ became depleted to less than one-half of control levels (Fig. $2 A$ ). Concomitantly, cAMP concentrations rose to $8 \pm 1.5 \mathrm{nmol} / 10^{6}$ cells (Fig. $2 \mathrm{D}$ ). The initial rise in cAMP was followed by a gradual decline lasting $>2 \mathrm{~h}$. In the rat the decline in cAMP was associated with a marked increase in $\operatorname{AMP}(11,21)$. By contrast, in human adipocytes virtually no increase in AMP was observed in conventional incubations, i.e., in the absence of inhibitors of ectophosphatase activities (Fig. $2 C$ ). As ADP levels also remained unchanged (Fig. $2 B$ ), the isoproterenolinduced drop in ATP was reflected by a corresponding decrease in total adenine nucleotide contents (Fig. $2 \mathrm{D}$ ).

Cell integrity and catabolism of extracellular adenine nucleotides. Human adipocytes are fragile (22). In standard incubations $8 \pm 2 \%$ of total cellular LDH activity was recovered in the media at the start of incubations. A further $8 \pm 2 \%$ was released per hour of incubation. During rapid time courses cell leakage was two to three times higher due to the more frequent agitation of suspensions (Table I). Catecholamines had no detectable influence on $\mathrm{LDH}$ release up to a concentration of 1 $\mu \mathrm{mol} / \mathrm{liter}$. Caution needs to be exercised at higher catecholamine concentrations, however. At $10 \mu \mathrm{mol} /$ liter $\mathrm{LDH}$ release may be increased up to twofold in some preparations, while no additional damage is observed in others (see legend to Fig. 3).

Human adipocytes possess ectophosphatases that are capable of sequentially degrading ATP to adenosine (15). Considering the short-lived integrity of the cells, it appeared important to discriminate between adenine nucleotide catabolism from broken cells, occurring extracellularly, and intracellular adenine nucleotide breakdown. Therefore, all subsequent experiments were carried out in the presence of $10 \mu \mathrm{mol} /$ liter $\alpha, \beta$ methylene adenosine $5^{\prime}$-diphosphate and $10 \mathrm{mmol} / \mathrm{liter} \beta$ glycerophosphate, which block the extracellular catabolism of ATP at the level of AMP $(23,24)$. The validity of this approach has been documented. ${ }^{2}$ Nonspecific losses of ATP result in a corresponding accumulation of ADP and AMP in the media under these conditions (Table I). Accordingly, the extracellular concentrations of these latter nucleotides (and cAMP) are related to $\mathrm{LDH}$ release in the absence and presence of isoproterenol, and no adenosine can be detected in the media because the extracellular catabolism of AMP is blocked (15). Notably, isoproterenol had only marginal effects, if any, on the intracellular concentrations of ADP and AMP in the presence of

Table I. Influence of a Maximal Concentration of Isoproterenol on cAMP Levels, Adenine Nucleotide Concentrations, and the Distribution of Individual Adenine Nucleotides

\begin{tabular}{|c|c|c|c|c|c|c|c|}
\hline \multirow[b]{2}{*}{ Additions } & & \multicolumn{2}{|c|}{ Suspensions } & \multicolumn{2}{|c|}{ Media } & \multicolumn{2}{|c|}{ Recovered in media } \\
\hline & & 0 min & $60 \mathrm{~min}$ & $0 \min$ & $60 \mathrm{~min}$ & $0 \mathrm{~min}$ & $60 \mathrm{~min}$ \\
\hline & & & & & & & \\
\hline \multirow[t]{5}{*}{ None } & ATP & $17.0 \pm 1.5$ & $11.4 \pm 0.9$ & \multicolumn{2}{|c|}{$\leq 0.2$} & & \\
\hline & ADP & $2.5 \pm 0.5$ & $3.6 \pm 0.7$ & $0.3 \pm 0.05$ & $2.3 \pm 0.6$ & & \\
\hline & AMP & $2.1 \pm 0.6$ & $3.4 \pm 0.4$ & $0.7 \pm 0.10$ & $3.9 \pm 0.4$ & & \\
\hline & $\mathrm{ATP}+\mathrm{ADP}+\mathrm{AMP}$ & $21.6 \pm 1.7$ & $18.2 \pm 1.4$ & $1.2 \pm 0.20$ & $6.2 \pm 1.0$ & 5 & 29 \\
\hline & LDH & \multicolumn{2}{|c|}{$2.7 \pm 0.3$} & $0.15 \pm 0.01$ & $0.8 \pm 0.1$ & 5 & 30 \\
\hline \multirow[t]{6}{*}{ Isoproterenol } & ATP & $17.4 \pm 1.5$ & $4.7 \pm 0.8$ & \multicolumn{2}{|c|}{$\leq 0.2$} & & \\
\hline & ADP & $2.9 \pm 0.4$ & $1.9 \pm 1.0$ & $0.3 \pm 0.05$ & $1.2 \pm 0.2$ & & \\
\hline & AMP & $1.1 \pm 0.2$ & $3.2 \pm 0.3$ & $0.6 \pm 0.10$ & $3.0 \pm 0.2$ & & \\
\hline & $\mathrm{ATP}+\mathrm{ADP}+\mathrm{AMP}$ & $21.4 \pm 1.6$ & $9.8 \pm 0.9$ & $1.1 \pm 0.20$ & $4.2 \pm 0.3$ & 4 & 20 \\
\hline & cAMP & 0.05 & $4.4 \pm 0.6$ & 0.01 & $2.4 \pm 0.2$ & - & 11 \\
\hline & LDH & \multicolumn{2}{|c|}{$2.8 \pm 0.3$} & $0.15 \pm 0.05$ & $0.9 \pm 0.13$ & 5 & 32 \\
\hline
\end{tabular}

Values are means $\pm \mathrm{SE}$ of the initial and final values ( $n=8$ for each condition) obtained in the rapid time courses summarized in Fig. 6 . Adenine nucleotide concentrations and $\mathrm{LDH}$ activity are given in terms of nanomoles $/ 10^{6}$ cells and units $/ 10^{6}$ cells, respectively. The media contained $10 \mu \mathrm{mol} /$ liter $\alpha, \beta$-methylene adenosine $5^{\prime}$-diphosphate and $10 \mathrm{mmol} / \mathrm{liter} \beta$-glycerophosphate either alone or in combination with 1 $\mu \mathrm{mol} /$ liter isoproterenol. 
inhibitors of ectophosphatase activities (Table I), consistent with the results obtained in conventional incubations (Fig. 2).

Effects of increasing concentrations of various catecholamines. Fig. 3 shows the effects of various concentrations of isoproterenol and epinephrine on cAMP levels, purine release, ATP, and the sum of individual adenine nucleotides. In contrast to isoproterenol, which is highly selective for $\beta$-adrenergic receptors, epinephrine has opposing $\alpha_{2}$ - and $\beta$-adrenergic effects on lipolysis and cAMP accumulation in human adipocytes (25). The effects of the naturally occurring catecholamine were therefore assessed in the absence and presence of the $\alpha_{2}$-blocking agent, yohimbine. Isoproterenol caused a concentration-dependent increase in cAMP which was half maximal at $0.3 \mu \mathrm{mol} /$ liter (Fig. $3 \mathrm{~A}$ ). Maximal effects were observed at an isoproterenol concentration of $3 \mu \mathrm{mol} /$ liter. Epinephrine alone caused only small increases in cAMP which were barely detectable in some experiments. On the average, cAMP levels were doubled by $1 \mu \mathrm{mol} / \mathrm{liter}$ epinephrine, a figure that contrasts to the more than 100 -fold elevation seen in the presence of $1 \mu \mathrm{mol} /$ liter isoproterenol. It was only in the presence of yohimbine that the naturally occurring catecholamine caused increases in cAMP that were comparable to those elicited by isoproterenol (Fig. $3 \mathrm{~A}$ ).

As shown in a preceeding paper (15), intact human adipocytes release extremely small amounts of adenosine, if any, irrespective of whether ATP turnover is increased by isoproterenol or not. Accordingly, the medium concentrations of this nucleoside were beyond detectable levels in the presence of $\alpha, \beta$-methylene adenosine 5 '-diphosphate and $\beta$-glycerophosphate. In contrast, isoproterenol and epinephrine (in the simultaneous presence of yohimbine) caused a marked increase in inosine and hypoxanthine release which closely resembled their cAMP-elevating effects with respect to relative efficacy and rank order of potency (Fig. $3 B$ ).

The stimulatory effects of both catecholamines on cAMP accumulation and purine release were inversely mirrored by a decrease in ATP and the sum of individual adenine nucleotides (Fig. 3, $C$ and $D$ ). All responses could be reversed by the $\beta$-blocking agent propranolol, indicating that they were mediated via a $\beta$-adrenergic receptor (Table II).

Somewhat surprisingly, isoproterenol and epinephrine (in the simultaneous presence of yohimbine) were more potent $(\sim 10$-fold $)$ in stimulating purine release than in increasing cAMP. This is more clearly illustrated in Fig. 4, showing the effects of increasing concentrations of isoproterenol on lipolysis, purine release, and cAMP accumulation in terms of a percentage of the maximal response. Lipolysis was most sensitive to isoproterenol. A maximal activation of purine release was observed at $0.3 \mu \mathrm{mol} /$ liter isoproterenol, whereas $3 \mu \mathrm{mol} / \mathrm{liter}$ was required for a maximal activation of cAMP accumulation.

For technical reasons, cAMP was measured at $20 \mathrm{~min}$, while purine release was assessed at $60 \mathrm{~min}$ of incubation. However, time courses of cAMP accumulation may vary with increasing concentrations of isoproterenol (26). Therefore, the relationship between cAMP accumulation and purine release was studied in detail at different concentrations of isoproterenol (Fig. 5). There was a slight shift in the peaks of cAMP accumulation from shorter to longer times with increasing concentrations of isoproterenol (Fig. $5 \mathrm{~A}$ ). In addition, cAMP levels tended to decline more slowly at high concentrations of the $\beta$-adrenergic agonist. Overall, the kinetic variability of cAMP accumulation was small, however, in relation to the marked difference in isoproterenol sensitivity noted between cAMP accumulation and purine release, indicating that this discrepancy is a real one (Fig. $5 \mathrm{~B}$ ).

An unexpected outcome of these studies was that purine release ceased as soon as cAMP had attained a relatively stable level, irrespective of whether cAMP levels remained markedly elevated or not. This is illustrated in Fig. 6 showing a balance of adenine nucleotide breakdown and formation of products, e.g., cAMP and purines. In controls, cAMP accumulation was negligible $\left(\sim 0.05 \mathrm{nmol} / 10^{6}\right.$ cells $)$, and purine release corre-

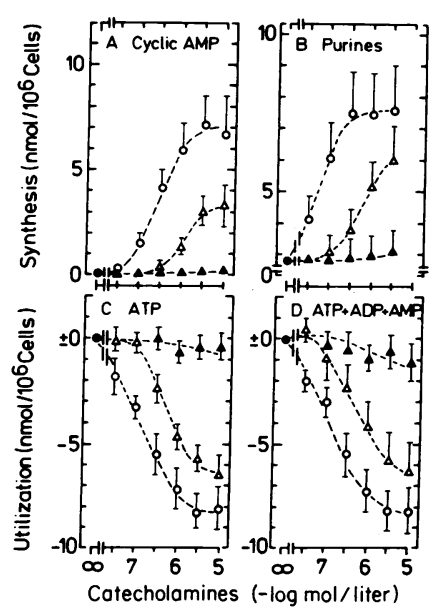

himbine $(\Delta)$. Baseline levels of ATP and total adenine nucleotides were in the range $12.5-13 \mathrm{nmol} / 10^{6}$ cells and $18-20 \mathrm{nmol} / 10^{6}$ cells, respectively. $\mathrm{LDH}$ release was similar in the absence $(14.5 \pm 5 \%)$ and presence $(14 \pm 6 \%)$ of $1 \mu \mathrm{mol} /$ liter isoproterenol, but was increased $(20 \pm 5 \%)$ at $10 \mu \mathrm{mol} / \mathrm{liter}$ of the $\beta$-adrenergic agonist. The media contained $10 \mathrm{mmol} / \mathrm{liter} \beta$-glycerophosphate and $10 \mu \mathrm{mol} / \mathrm{liter} \alpha, \beta$ methylene adenosine 5 '-diphosphate.
Figure 3. Effects of increasing concentrations of different catecholamines on cAMP accumulation, purine release, ATP levels, and the sum of individual adenine nucleotides. Values are means \pm SE of seven separate experiments for each condition. cAMP and adenine nucleotides were determined in neutralized perchloric acid extracts of suspensions after 20 min of incubation. Purines were assayed at $60 \mathrm{~min}$. Symbols refer to the effects of isoproterenol (o) or epinephrine, either alone ( $\Lambda)$, or in combination with $1 \mu \mathrm{mol} /$ liter yo-
Table II. Comparison of the Effects of Propranolol When Added Simultaneously with, or Subsequent to, Exposure to Isoproterenol

\begin{tabular}{lc}
\hline \multicolumn{1}{c}{ Addition } & Purines \\
\hline & $\mathrm{nmol} \cdot 10^{-6} \mathrm{cells} \cdot 60 \mathrm{~min}^{-1}$ \\
None & $2.2 \pm 0.9$ \\
Isoproterenol at $0 \mathrm{~min}$ & $7.2 \pm 2.0$ \\
Isoproterenol at $0 \mathrm{~min}$ & \\
$\quad+$ propranolol at $0 \mathrm{~min}$ & $2.5 \pm 1.0$ \\
None & $1.8 \pm 0.4$ \\
Isoproterenol at $0 \mathrm{~min}$ & $6.0 \pm 0.5$ \\
Isoproterenol at $0 \mathrm{~min}$ & \\
$\quad+$ propranolol at $30 \mathrm{~min}$ & $5.4 \pm 0.6$ \\
\end{tabular}

Values are means $\pm \mathrm{SE}$ of three paired experiments in both experimental settings. Suspensions contained $27,000 \pm 3,000$ cells/ml (propranolol at $0 \mathrm{~min}$ ), and $34,000 \pm 2,500$ cells $/ \mathrm{ml}$ (propranolol at 30 $\mathrm{min}$ ). The final concentrations of isoproterenol and propranolol were 1 and $2 \mu \mathrm{mol} /$ liter, respectively. The media contained $10 \mathrm{mmol} / \mathrm{liter}$ $\beta$-glycerophosphate and $10 \mu \mathrm{mol} /$ liter $\alpha, \beta$-methylene adenosine $5^{\prime}$-diphosphate. 


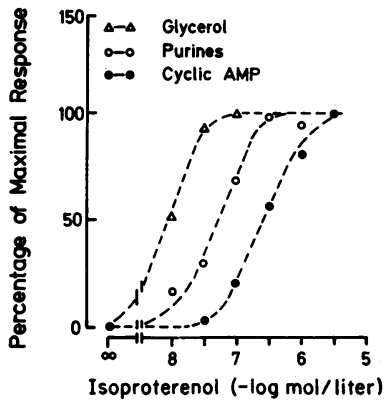

Figure 4. Isoproterenol sensitivity of various $\beta$-adrenergic receptormediated responses. Values are normalized means of the data obtained in the experiments shown in Fig. 3, where details are given.

sponded to $<10 \%$ of cellular adenine nucleotide contents. After a small initial drop, adenine nucleotide concentrations, therefore, remained essentially unchanged in the course of incubations (Fig. 6 B).

Isoproterenol caused a drop in adenine nucleotide concentrations by half. Initially the decrease in adenine nucleotide concentrations could be mainly accounted for by the isoproterenol-induced increase in cAMP. The subsequent transition to a lower relatively stable cAMP level was counterbalanced by the ongoing release of purines. Thereafter purine release ceased even though cAMP concentrations were still $>100$ times above basal levels. Concomitantly, adenine nucleotide concentrations were stabilized at the same low level that was initially attained, and the sum of cAMP and purines closely corresponded to the decrease in adenine nucleotide concentrations in the whole course of incubations (Fig. $6 \mathrm{~A}$ ). Consistently, propranolol could only prevent the isoproterenol-induced increase in purine release when added at the start of incubations, but had little effect after $30 \mathrm{~min}$ (Table II).

Effects of phosphodiesterase inhibitors. The isoproterenolinduced drop in ATP and total adenine nucleotides could be the result of increased substrate consumption via adenylate cyclase as well as increased ATP-utilizing activities that are stimulated by the elevated cAMP level. cAMP became a major adenine nucleotide in the presence of maximal concentrations of $\beta$-adrenergic agonists, suggesting that the former mechanism is the more important one. The latter concept implies that phosphodiesterase is one of the critical steps in the chain of events leading to a hormone-induced increase in adenine nucleotide catabolism.

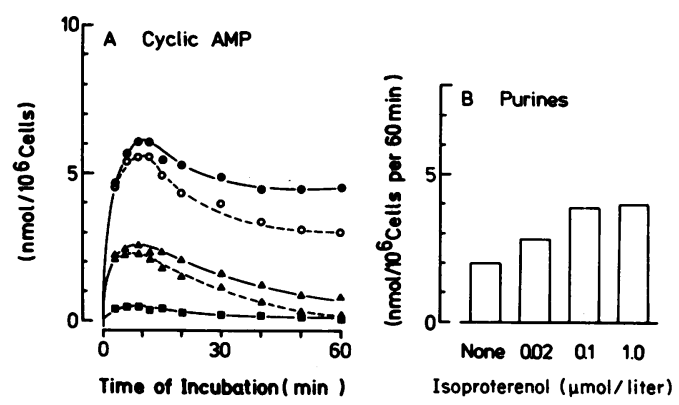

Figure 5. Relation between cAMP accumulation and purine release with increasing concentrations of isoproterenol. $A$, Values are means of duplicate determinations obtained in one out of three experiments and refer to cAMP contents of suspensions (closed symbols) and intracellular levels of the cyclic nucleotide (open symbols) at $1 \mu \mathrm{mol} /$ liter (circles), $0.1 \mu \mathrm{mol} /$ liter (triangles), and $0.02 \mu \mathrm{mol} /$ liter (square) isoproterenol, respectively. $B$, Purines were determined after $60 \mathrm{~min}$ of incubation.

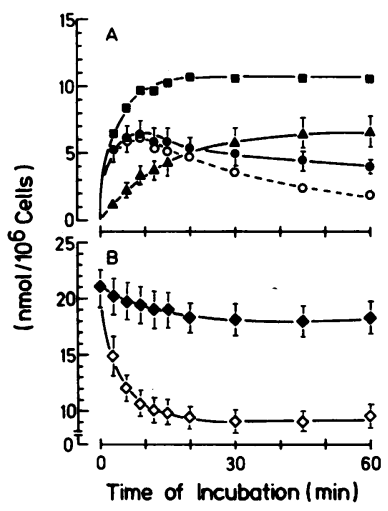

Figure 6. Temporal interrelationship between isoproterenol-induced cAMP accumulation and its stimulatory effect on purine release: contribution of each response to the $\beta$-adrenergic receptor-mediated depletion of cellular adenine nucleotide contents. $A$, Kinetics of cAMP accumulation inside the cells (O) and in suspensions (๑), and time course of purine release $(\Delta)$ in the presence of $1 \mu \mathrm{mol} /$ liter isoproterenol. Quadratic symbols refer to the sum of cAMP and purines recovered in suspensions. $B$, Concomitant changes in total adenine nucleotide contents of suspensions in the absence $(\bullet)$ and presence $(\diamond)$ of isoproterenol. Values are means $\pm \mathrm{SE}$ of the experiments summarized in Table I. The media contained $10 \mathrm{mmol} / \mathrm{liter} \beta$-glycerophosphate and $10 \mu \mathrm{mol} /$ liter $\alpha, \beta$-methylene adenosine 5'-diphosphate.

Indeed, the phosphodiesterase inhibitors, IBMX and Ro 20-1724, inhibited the increase in purine release seen in the presence of isoproterenol in a concentration-dependent manner (Fig. 7, Table III). Half-maximal effects were observed at $0.1 \mu \mathrm{mol} /$ liter Ro 20-1724 and $0.3 \mathrm{mmol} / \mathrm{liter} \mathrm{IBMX}$, respectively. At $1 \mu \mathrm{mol} /$ liter both compounds caused a virtually complete inhibition of purine release in the presence of 1 $\mu \mathrm{mol} /$ liter isoproterenol (Fig. 7, Table III). The inhibition of purine release was associated with a marked increase in cAMP, indicating that the cyclic nucleotide is in fact the main precursor of purines in the presence of isoproterenol (Fig. 7, Table III).

Reversibility of the catecholamine-induced decrease in adenine nucleotide concentrations. As shown in a recent report (15), adenosine was avidly taken up and incorporated into cellular adenine nucleotides (Table IV). In contrast to adenosine, the concentrations of exogenously supplied inosine and hypoxanthine ( $1 \mu \mathrm{mol} / \mathrm{liter})$ dropped by $<10 \%$ within $3 \mathrm{~h}$, indicating that human adipocytes can reutilize only small amounts of these latter purines, if any (Table IV). Along with the observation that $\beta$-adrenergic agonists caused a selective increase in inosine and hypoxanthine release, the latter finding strongly suggested that the catecholamine-induced drop in cellular adenine nucleotide contents is largely irreversible.

To substantiate this contention suspensions were incubated in the absence and presence of isoproterenol, either alone or in combination with the phosphodiesterase inhibitor, Ro 20-1724. After $30 \mathrm{~min}$ the stimulatory action of isoproter-

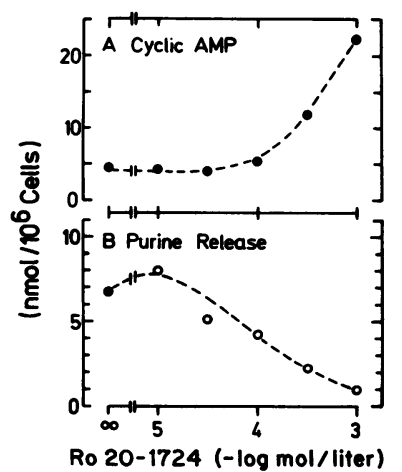

Figure 7. Effects of increasing concentrations of Ro 20-1724 on isoproterenol-activated rates of cAMP accumulation and purine release. The media contained 10 $\mu \mathrm{mol} /$ liter $\alpha, \beta$-glycerophosphate, $10 \mathrm{mmol} /$ liter $\beta$-glycerophosphate, and $1 \mu \mathrm{mol} /$ liter isoproterenol. Values refer to cAMP contents of suspensions and purine concentrations in heat-inactivated media and are means of duplicate determinations. 
Table III. Effects of IBMX on Isoproterenol-stimulated cAMP Accumulation and Purine Release

\begin{tabular}{lcr}
\hline \multicolumn{1}{c}{ Addition } & Purines & \multicolumn{1}{c}{ cAMP } \\
\hline & \multicolumn{2}{c}{$n m o l \times 10^{-6}$ cells } \\
& $7.7 \pm 1.8$ & $7 \pm 3$ \\
Isoproterenol & $1.0 \pm 0.4$ & $15 \pm 4$ \\
Isoproterenol + IBMX & & \\
\hline
\end{tabular}

Suspensions $(32,000 \pm 3,000$ cells $/ \mathrm{ml})$ were preincubated for $30 \mathrm{~min}$ in the absence or presence of $1 \mathrm{mmol} / \mathrm{liter}$ IBMX. Thereafter, preincubation media were replaced by fresh media and incubations were continued for another $30 \mathrm{~min}$ in the presence of $1 \mu \mathrm{mol} /$ liter isoproterenol either alone or in combination with $1 \mathrm{mmol} /$ liter IBMX. Values are means \pm SE of three separate experiments carried out with fat cells from different donors and refer to medium concentrations of purines and cAMP contents of suspensions, respectively. The media contained $10 \mathrm{mmol} /$ liter $\beta$-glycerophosphate and $10 \mu \mathrm{mol} /$ liter $\alpha, \beta$ methylene adenosine 5 -diphosphate.

enol was terminated by $2 \mu \mathrm{mol} /$ liter propranolol and incubations were continued for another $60 \mathrm{~min}$ (Fig. 7). Propranolol had no influence on purine release when added after $30 \mathrm{~min}$, consistent with the data shown in Table II. By contrast, cAMP concentrations rapidly declined after addition of the $\beta$-blocking agent (Fig. $8 \mathrm{~A}$ ). The cAMP that was still present $15 \mathrm{~min}$ after addition of propranolol was almost quantitatively recovered in the media, indicating that the intracellular concentrations of the cyclic nucleotide had approached basal levels. Concomitantly, adenine nucleotide concentrations rose to a new steady level which was, however, lower than the initial one (Fig. $8 \mathrm{C}$ ). The difference between the initial and final adenine nucleotide concentrations closely corresponded to the sum of cAMP and purines recovered in the media, indicating that the catecholamine-induced depletion of ATP and total cellular adenine nucleotides is in fact largely irreversible (Fig. $8 \mathrm{C}$ ).

In the presence of a maximally effective concentration of Ro 20-1724 (0.75 mmol/liter), the isoproterenol-induced increase in cAMP was doubled (Fig. 8 B). The phosphodiesterase inhibitor delayed the decay of cAMP as expected. However, its influence on the activity of phosphodiestere(s) in situ was relatively small. The half-life of cAMP was $\sim 4 \mathrm{~min}$ in the absence of the phosphodiesterase inhibitor and $7.5 \mathrm{~min}$ in its presence. As cAMP concentrations were doubled by Ro 20-1724, it is

Table IV. Removal of Exogenously Supplied Purines

\begin{tabular}{lcc}
\hline \multirow{2}{*}{ Addition } & \multicolumn{2}{c}{ Purines } \\
\cline { 2 - 3 } & \multicolumn{3}{c}{$0 \mathrm{~min}$} & $180 \mathrm{~min}$ \\
\hline Adenosine & $0.98 \pm 0.05$ & $0.18 \pm 0.03$ \\
Inosine & $1.04 \pm 0.07$ & $0.92 \pm 0.05$ \\
Hypoxanthine & $0.98 \pm 0.04$ & $0.89 \pm 0.05$ \\
\hline
\end{tabular}

Suspensions $(38,000 \pm 5,000$ cells $/ \mathrm{ml})$ were incubated in the presence of $1 \mu \mathrm{mol} /$ liter of exogenously supplied purines. Values are means $\pm \mathrm{SE}$ of three paired experiments carried out as time-course studies and the initial and final values are given. The media contained $10 \mathrm{mmol} / \mathrm{liter} \beta$-glycerophosphate and $10 \mu \mathrm{mol} / \mathrm{liter} \alpha, \beta$ methylene adenosine 5'-diphosphate. intuitively clear that at steady state the inhibitor of phosphodiesterase(s) had little, if any, influence on cAMP metabolic flux. Nonetheless, purine release was blunted (Fig. 8 B). In contrast to controls (Fig. 8, $A$ and $C$ ), the isoproterenol-induced drop in adenine nucleotide concentrations was almost completely reversible in the presence of Ro 20-1724 (Fig. 8 D). The relatively small losses of cellular adenine nucleotides $(\sim 10 \%)$ could be mainly accounted for by the amount of cAMP recovered in the media under these latter conditions (Fig. 8 D).

\section{Discussion}

It is well established that $\beta$-adrenergic stimulation of fat cell lipolysis may be associated with a pronounced drop in ATP (1-3). However, no previous study has followed the concentrations of other adenine nucleotides and their degradation products in a manner adequate for a quantitative assessment of the pathways of energy metabolism in adipocytes. The present study demonstrates that in human adipocytes the ATPlowering action of $\beta$-adrenergic catecholamines is almost entirely due to their cAMP-elevating property. The hydrolysis of cAMP is associated with a stimulation of adenine nucleotide breakdown which leads to an irreversible loss of adenine nucleotides.

Effects of catecholamines on cAMP levels and adenine nucleotide concentrations. The rate of adenine nucleotide breakdown may be accelerated by an increase in ATP utilization, a decrease in the ability of cells to phosphorylate ADP and AMP, or both these mechanisms (14). As nearly three times

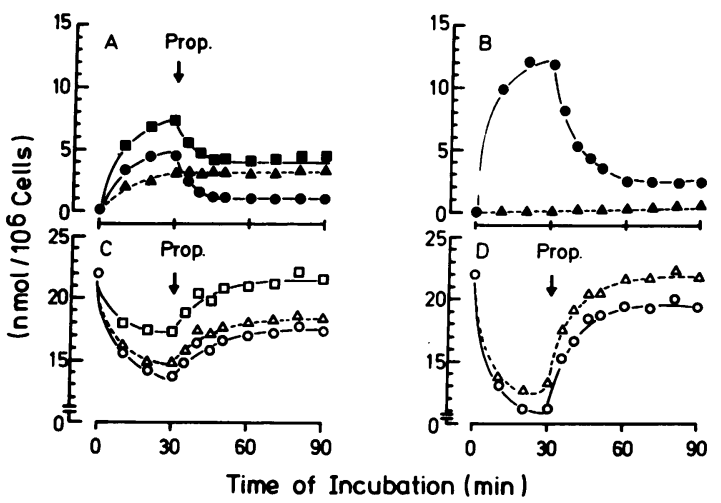

Figure 8. Irreversibility of the isoproterenol-induced depletion of cellular adenine nucleotide contents: effects of Ro 20-1724. Suspensions $(32,000 \pm 3,000 \mathrm{cells} / \mathrm{ml})$ were preincubated in the absence $(A, C)$ or presence $(B, D)$ of $0.75 \mathrm{mmol} /$ liter Ro $20-1724$ for $15 \mathrm{~min}$, and then exposed to $1 \mu \mathrm{mol} /$ liter isoproterenol. After a further $30 \mathrm{~min}, 2$ $\mu \mathrm{mol} /$ liter propranolol (Prop.) was added and incubations were continued for another $60 \mathrm{~min}$. In $A$ and $B$ the effects of propranolol on cAMP contents of suspensions $(\bullet)$ and the net release of purines $(\Delta)$ in the absence $(A)$ or presence $(B)$ of the phosphodiesterase inhibitor are shown. $n$, The sum of cAMP and purine contents of suspensions. $C$ and $D$ illustrate the concomitant changes in adenine nucleotide contents of suspensions $(0)$ and the sum of individual adenine nucleotides in suspensions plus cAMP in media $(\Delta)$. $\square$, Sum of adenine nucleotides and the products of adenine nucleotide metabolism, e.g., cAMP in media and purines. The media contained $10 \mathrm{mmol} /$ liter $\beta$ glycerophosphate and $10 \mu \mathrm{mol} /$ liter $\alpha, \beta$-methylene adenosine 5 '-diphosphate. Values are means of four separate experiments in each condition. 
more fatty acids were released than glycerol, an increase in ATP utilization due to an activation of the lipolysis-reesterification cycle can be ruled out (4-7). Likewise, an inhibition of ATP synthesis by uncomplexed fatty acids is unlikely to play a role because the molar FFA to albumin ratio was $<3: 1$ in the present experiments, indicating that the tight-binding capacity of albumin for fatty acids had not been exceeded (27). The pathway involving cAMP formation and hydrolysis is generally not considered a major route of ATP utilization (4). By contrast, in the present experiments the majority of ATP was converted to CAMP within $15 \mathrm{~min}$ in the presence of isoproterenol (Figs. 2 and 6). The latter finding points out the considerable potential of adenylate cyclase and demonstrates that the pathway involving the formation and hydrolysis of cAMP assumes a major role in ATP utilization in the presence of maximally effective concentrations of $\beta$-adrenergic catecholamines. Similar observations were made in the rat $(11,21)$. However, in rat adipocytes the catecholamine-induced drop in ATP was associated with a major change in adenine nucleotide distribution (i.e., AMP became the predominant nucleotide), while the sum of individual adenine nucleotides displayed no major change $(11,21)$. By contrast, in human adipocytes the concentrations of ADP and AMP were not substantially altered in spite of a marked drop in ATP. Along with the observation that cAMP levels remained elevated for $>1 \mathrm{~h}$ in the presence of maximal concentrations of $\beta$-adrenergic agonists, the latter finding suggests that the rate of AMP formation is largely determined by the velocity of cAMP hydrolysis in the presence of $\beta$-adrenergic agonists.

Once formed, AMP may be reconverted to ATP through the action of adenylate kinase or degraded by deamination and/or dephosphorylation (14). In human adipocytes AMP breakdown takes place primarily by deamination. ${ }^{2}$ Indeed, the catecholamine-induced increase in ATP turnover via adenylate cyclase resulted in a concentration-dependent increase in release of inosine and hypoxanthine, which cannot be reutilized for adenine nucleotide synthesis by human adipocytes. Accordingly, the catecholamine-induced drop in ATP and total adenine nucleotide concentrations was largely irreversible. Overall, the current data thus strongly suggest that the pathway involving cAMP formation and hydrolysis not only assumes a major role in ATP utilization (which is reversible), but also constitutes the principle route of irreversible adenine nucleotide catabolism in the presence of $\beta$-adrenergic agonists.

Role of phosphodiesterase. Recent studies in rat adipocytes demonstrated a reversible drop in ATP in the simultaneous presence of phosphodiesterase inhibitors and catecholamines (11). Consistently, the irreversible loss of preformed purine bases was prevented by this type of drug in the current experiments, and the isoproterenol-induced depletion of cellular adenine nucleotide contents was nearly fully reversible (Fig. 8). The use of phosphodiesterase inhibitors is not simple, however, in that they cause only transient inhibition of cAMP hydrolysis in situ, and may show other effects as well (28). Since the inhibitory effects of IBMX and Ro 20-1724 on catecholamine-induced adenine nucleotide catabolism were associated with an excessive increase in CAMP, an effect of both on phosphodiesterase may be inferred (Fig. 7). Furthermore, as discussed below, the stimulatory effects of $\beta$-adrenergic agonists on purine release appear to be related to the initial burst of cAMP turnover, and this explains why IBMX and Ro 20-1724 were capable of completely suppressing adenine nu- cleotide catabolism, even though their inhibitory effects were rapidly overcome in association with increasing levels of cAMP. Overall, it thus appears that the catecholamine-induced loss of preformed purine bases is in fact critically dependent on phosphodiesterase activity.

Phosphodiesterase exists in multiple forms which vary widely in substrate affinities and mode of regulation (26, 28-32). Among the at least three isoforms that are present in rat fat cells, a low $K_{\mathrm{m}}$ cAMP phosphodiesterase has been identified that is activated by catecholamines (presumably through the action of a cAMP-dependent protein kinase; 31 ). The enzyme is also present in human adipocytes (30). The issue of whether or not the increase in enzyme activity observed in broken cell preparations relates to the intact cell remains to be clarified. It is, therefore, difficult to decide whether the catecholamine-induced acceleration of AMP catabolism is solely due to increased availability of its precursor cAMP, or reflects (at least in part) regulatory influences at the level of hormonesensitive cAMP phosphodiesterase. The striking parallelism between the cAMP-elevating properties of epinephrine and isoproterenol and their stimulatory effects on purine release suggests that increased substrate availability is one of the factors that are causally involved. However, both catecholamines were more potent in stimulating purine release than in eliciting an increase in cAMP. A series of reports, including this study, have shown that a similar discrepancy exists between the cAMP-elevating properties of catecholamines and their stimulatory effects on lipolysis, which may reflect a compartmentation of the cyclic nucleotide, but could be caused by other mechanisms as well (32-34). The former possibility is supported by the work of Goldberg et al. demonstrating stimulusinduced increases in cyclic nucleotide turnover which were transient, and appeared to reflect a highly coordinated increase in cyclic nucleotide formation and hydrolysis confined to functionally important pools (10). The observation that purine release ceased as soon as CAMP had attained relatively stable levels strongly suggests that similar mechanisms are operative in human adipocytes (Fig. 6). As cAMP levels remained markedly elevated, the progressive decrease in purine release can be classified as a homologous type of desensitization (4). Intriguingly, partially purified preparations of hormone-sensitive fat cell phosphodiesterase display the same type of response during sustained $\beta$-adrenergic stimulation (32). The questions of whether and to what extent the stimulatory effects of catecholamines on purine release reflect their effects on hormone-sensitive phosphodiesterase, therefore, deserve further investigation.

Physiological considerations. Previous work from this and other laboratories revealed that the elimination of inhibitory influences is sufficient for fat cells to achieve lipolytic activities that are comparable with those observed in the presence of a maximal concentration of isoproterenol (35-37). As activating hormones are not necessary for a maximal stimulation of lipid mobilization, it was concluded that human fat cell lipolysis needs to be inhibited before it can be activated by lipolytic hormones (37). By demonstrating that unopposed stimulatory inputs can lead to an irreversible depletion of cellular energy stores, the present findings provide further arguments in support of the view that a certain degree of inhibition is essential for the maintenance of metabolic homoiostasis in fat cells.

Along this line of reasoning it is difficult to understand why the cells fail to release adenosine, which, in contrast to inosine 
and hypoxanthine, is capable of preventing an excessive production of cAMP and can be reutilized for adenine nucleotide synthesis $(11,12,35-37)$. In vivo, the interstitial fluid of human adipose tissue appears to contain adenosine, however, which may be derived from the circulation or produced locally by vascular stromal cells or neurons (38). In addition, epinephrine and norepinephrine are the only hormones that have been demonstrated to be of physiological importance as stimulators of lipid mobilization in adult humans (22). Both hormones have antagonistic $\alpha_{2}$ - and $\beta$-adrenergic components of action (25). Therefore, the degree of $\beta$-adrenergic stimulation observed in the presence of maximal concentrations of isoproterenol will never occur in vivo (Fig. 3). The questions of whether and how a dual regulation of a single metabolic pathway by a single class of hormones might offer advantages over an unidirectional type of control have not been satisfactorily answered until now. This study points out that this type of regulation may play a role in minimizing the energy that is wasted by signal transmission, implying that rat adipocytes that are devoid of functional $\alpha_{2}$-adrenergic receptors might be more dependent on inhibitory regulators such as adenosine than human adipocytes (22).

Therapeutic implications. A series of reports have shown that the $\beta$-adrenergic receptors of human and rat fat cells do not conform to the $\beta_{1} / \beta_{2}$ classification $(39,40)$. Other studies indicate that in the rat brown adipocytes have similar $\beta$ adrenergic receptors (41). Compounds that selectively stimulate brown adipocyte $\beta$-adrenergic receptors are currently being tested for their potential as thermogenic antiobesity drugs. However, brown adipose tissue is scarce in adult human beings (42). It is therefore doubtful whether the oxidative capacity of this energetically wasteful tissue is large enough to make a substantial contribution to energy expenditure in man. The present findings document that white fat cells have an enormous potential for dissipating energy in response to $\beta$ adrenergic catecholamines, suggesting that white adipose tissue, which is present in excessive amounts in the obese, may be a much more important target of thermogenic drugs in human beings than brown adipose tissue.

In conclusion, it is shown that $\beta$-adrenergic activation of human fat cell lipolysis results in a marked increase in inosine and hypoxanthine release which is closely related to cAMP accumulation. In contrast to adenosine, inosine and hypoxanthine cannot be reutilized for adenine nucleotide synthesis. Unopposed $\beta$-adrenergic stimulation therefore leads to an irreversible loss of cellular adenine nucleotides which is not seen in the presence of the naturally occurring hormone, epinephrine, acting through $\alpha_{2}$ - and $\beta$-adrenergic receptors.

\section{Acknowledgments}

The author is indebted to B. Löser, E. Messmer, B. Nessel, and B. Sattel for expert technical assistance, and wishes to thank C. Brown for careful preparation of the manuscript. cAMP determinations were kindly performed by $V$. Herrmann.

This work was supported by grants from the Deutsche Forschungsgemeinschaft and the Bundesministerium für Forschung und Technologie (Förderungskennzeichen 0704721-AZ), Bonn, FRG.

\section{References}

1. Jeanrenaud, B., D. Hepp, and A. E. Renold. 1970. The influence of lipolysis on energy metabolism of isolated fat cells. In Adipose
Tissue: Regulation and Metabolic Functions. R. Levine, E. F. Pfeiffer, B. Jeanrenaud, and D. Hepp, editors. Georg Thieme Verlag, Stuttgart. 76-79.

2. Angel, A., K. S. Desai, and M. L. Halpern. 1971. Reduction in adipocyte ATP by lipolytic agents: relation to intracellular free fatty acid accumulation. J. Lipid Res. 12:203-213.

3. Heindel, J. J., S. W. Cushman, and B. J. Jeanrenaud. 1974. Cell-associated fatty acid levels and energy-requiring processes in mouse adipocytes. Am. J. Physiol. 226:16-24.

4. Martin, B. R. 1987. Metabolic Regulation: A Molecular Approach. Blackwell Scientific Publications Ltd., Oxford, UK. 299 pp.

5. May, J. M. 1982. Triacylglycerol turnover in large and small rat adipocytes: effects of lipolytic stimulation, glucose and insulin. J. Lipid Res. 23:428-436.

6. Brooks, B., J. R. S. Arch, and E. A. Newsholme. 1982. Effects of hormones on the rate of the triacylglycerol/fatty acid substrate cycle in adipocytes and epididymal fat pads. FEBS (Fed. Eur. Biochem. Soc.) Lett. 146:327-330.

7. Leibel, R. L., and J. Hirsch. 1985. A radioisotopic technique for analysis of free fatty acid reesterification in human adipose tissue. $\mathrm{Am}$. J. Physiol. 248:E140-E147.

8. Hammond, V. A., and D. G. Johnston. 1987. Substrate cycling between triglyceride and fatty acids in human adipocytes. Metab. Clin. Exp. 36:308-313.

9. Fain, J. N., and R. E. Shepard. 1975. Free fatty acids as feedback regulators of adenylate cyclase and cyclic 3',5'-AMP accumulation in rat fat cells. J. Biol. Chem. 250:6586-6592.

10. Goldberg, N. D., T. F. Walseth, S. J. Eick, T. P. Krick, B. L. Kuehn, and J. E. Gander. 1984. Cyclic AMP metabolism in intact platelets determined by ${ }^{18} \mathrm{O}$ incorporation into adenine nucleotide $\alpha$ phosphoryls. Adv. Cyclic Nucleotide Protein Phosphorylation Res. 16:363-379.

11. Chung, F. Z., H. W. Weber, and M. M. Applemann. 1985. Extensive but reversible depletion of ATP via adenylate cyclase in rat adipocytes. Proc. Natl. Acad. Sci. USA. 82:1614-1617.

12. Schwabe, U., R. Ebert, and H. G. Erbler. 1973. Adenosine release from isolated fat cells and its significance for the effects of hormones on cyclic 3',5'-AMP levels and lipolysis. Naunyn-Schmiedeberg's Arch. Pharmacol. 276:133-148.

13. Barber, R., and T. J. Goka. 1981. Cyclic AMP turnover in S49 cells. J. Cyclic Nucleotide Res. 7:353-361.

14. Bidger, W. A., and F. A. Henderson. 1983. Cell ATP. John Wiley \& Sons. New York. 170 pp.

15. Kather, H. 1988. Purine accumulation in human fat cell suspensions: evidence that human adipocytes release inosine and hypoxanthine rather than adenosine. J. Biol. Chem. 263:8803-8809.

16. Rodbell, M. 1964. Metabolism of isolated fat cells. J. Biol. Chem. 239:375-384.

17. Kather, H., and E. Wieland. 1985. Free fatty acids: luminometric method. Methods Enzymatic Analysis. 8:25-34.

18. Kather, H., and E. Wieland. 1984. Glycerol: luminometric method. Methods Enzymatic Analysis. 6:510-518.

19. Kather, H., E. Wieland, and W. Waas. 1987. Chemiluminescent determination of adenosine, inosine and hypoxanthine/xanthine. Anal. Biochem. 163:45-51.

20. Spielmann, H., U. Jacob-Müller, and P. Schultz. 1981. Simple assay of 0.1-1 pmol ATP, ADP, AMP in single somatic cells using purified luciferin luciferase. Anal. Biochem. 193:172-178.

21. Fain, J. N. 1979. Effect of lipolytic agents on adenosine and AMP-formation by rat fat cells. Biochim. Biophys. Acta. 573:510-520.

22. Hales, C. N., J. P. Luzio, and K. Siddle. 1978. Hormonal control of adipose tissue lipolysis. Biochem. Soc. Symp. 43:97-135.

23. Gordon, E. L., J. D. Pearson, and L. L. Slakey. 1986. The hydrolysis of extracellular adenine nucleotides by cultured endothelial cells from pig aorta: feed-forward inhibition of adenosine production at the cell surface. J. Biol. Chem. 261:15496-15504.

24. Collinson, A. R., K. J. Peuhkurinen, and J. M. Lowenstein. 1987. Regulation and function of 5'-nucleotidases. In Topics and Per- 
spectives in Adenosine Research. E. Gerlach and B. F. Becker, editors. Springer-Verlag, Berlin. 133-144.

25. Kather, H., and B. Simon. 1981. Adrenoceptor of the alpha-2subtype mediating inhibition of the human fat cell adenylate cyclase. Eur. J. Clin. Invest. 11:111-114.

26. Butcher, R. W. 1984. Phosphodiesterase after twenty years: an introduction. Adv. Cyclic Nucleotide Protein Phosphorylation Res. 16:1-11.

27. Reed, G. R. 1986. Location of long chain fatty acid binding sites of bovine serum albumin by affinity labeling. J. Biol. Chem. 261:15619-15624.

28. Beavo, J. A. 1988. Multiple isozymes of cyclic nucleotide phosphodiesterase. Adv. Second Messenger Phosphoprotein Res. 22:1-38.

29. Degerman, E., P. Belfrage, A. Hauck-Newman, K. C. Rice, and V. C. Manganiello. 1987. Purification of the putative hormone-sensitive cyclic AMP phosphodiesterase from rat adipose tissue using a derivative of cilostamide as a novel affinity ligand. J. Biol. Chem. 262:5797-5897.

30. Engfeldt, P., P. Arner, and J. Östman. 1983. Studies on the regulation of phophodiesterase in human adipocytes in vitro. J. Clin. Endocrinol. Metab. 56:501-506.

31. Gettys, T. W., A. J. Vine, M. F. Simmonds, and J. D. Corbin. 1988. Activation of particulate low $K_{\mathrm{m}}$ phosphodiesterase of rat adipocytes by addition of cAMP-dependent protein kinase. J. Biol. Chem. 263:10359-10363.

32. Manganiello, V., E. Degerman, and M. Elks. 1988. Selective inhibitors of specific phosphodiesterases in intact adipocytes. Methods Enzymol. 188:504-521.

33. Cobb, C. E., A. H. Beth, and J. D. Corbin. 1987. Purification and characterization of an inactive form of cAMP-dependent protein kinase containing bound cAMP. J. Biol. Chem. 262:16566-16574.
34. Hoffman, B. B., P. Prokocimer, J. M. Thomas, R. Vagelos, H. Chang, and G. M. Reaven. 1989. Cellular tolerance to adenosine receptor-mediated inhibition of lipolysis: altered adenosine 3',5'-monophosphate metabolism and protein kinase activation. Endocrinology. 124:2434-2442.

35. Schwabe, U., and R. Ebert. 1974. Stimulation of cyclic adenosine 3 '-5'-monophosphate accumulation and lipolysis in fat cells by adenosine deaminase. Naunyn-Schmiedeberg's Arch. Pharmacol. 282:33-44.

36. Honnor, R. C., S. Gurpreet, and C. Londos. 1985. cAMP-dependent protein kinase and lipolysis in rat adipocytes. II. Definition of steady state relationship with lipolytic and antilipolytic modulators. $J$. Biol. Chem. 260:15130-15138.

37. Kather, H., W. Bieger, G. Michel, K. Aktories, and K. H. Jakobs. 1985 . Human fat cell lipolysis is primarily regulated by inhibitory modulators acting through distinct mechanisms. J. Clin. Invest. 76:1559-1565.

38. Lönnroth, P., P. A. Jansson, B. B. Fredholm, and U. Smith. 1989. Microdialysis of intercellular adenosine concentration in subcutaneous tissue in humans. Am. J. Physiol. 256:E250-E255.

39. Wilson, C., S. Wilson, V. Piercy, M. V. Sennit, and J. R. S. Arch. 1984. The rat lipolytic $\beta$-adrenoceptor: studies using novel $\beta$ adrenoceptor agonists. Eur. J. Pharmacol. 100:309-319.

40. Kather, H., and B. Simon. 1980. Effects of salbutamol and butoxamine on the human fat cell adenylate cyclase. Horm. Metab. Res. 12:695-697.

41. Arch, J. R. S., A. T. Ainsworth, M. A. Cawthorne, V. Piercy, M. V. Sennit, V. E. Thody, C. Wilson, and S. Wilson. 1984. Atypical $\beta$-adrenoceptor on brown adipocytes as target for anti-obesity drugs. Nature (Lond.). 309:163-165.

42. Rothwell, N. J., and M. J. Stock. 1979. A role for brown adipose tissue in diet-induced thermogenesis. Nature (Lond.). 281:31-35. 